\title{
Evaluation of IMIS7
}

\section{Micah D Gale, Patrick Tyler Eblen, Nancy J Lybeck, Douglas L Porter}

November 2019

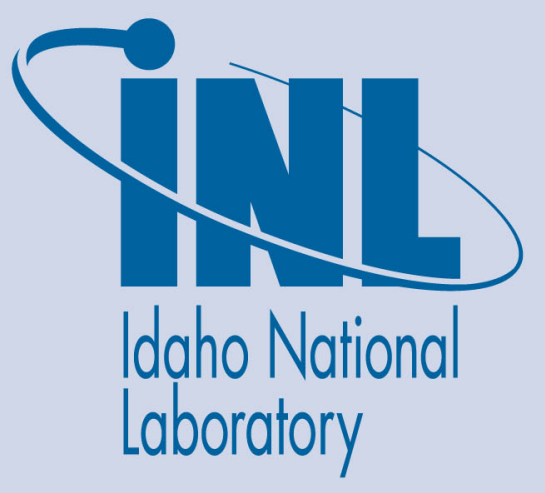

The INL is a U.S. Department of Energy National Laboratory operated by Battelle Energy Alliance 
INL/MIS-19-56233-Revision-0

\title{
Evaluation of IMIS7
}

Micah D Gale, Patrick Tyler Eblen, Nancy J Lybeck, Douglas L Porter

November 2019

\section{Idaho National Laboratory Idaho Falls, Idaho 83415}

http://www.inl.gov

\author{
Prepared for the
}

U.S. Department of Energy

Office of Nuclear Energy, Office of Nuclear Energy

Under DOE Idaho Operations Office

Contract DE-AC07-05ID14517, DE-AC07-05ID14517 


\section{Databases to Support Modeling/Fuel Qualification}

\section{Doug Porter}

November 1, 2019

TIIII 


\section{LDRD Concept}

\section{Modeling - Use data for validation of models}

\section{Is this easy now? - NO for IMIS (reason for LDRD); FIPD?}

Data sorted by assembly; need cladding type, fuel type, operating temperature range, linear power density, etc.

Fuel pin design information inadequate; store drawings in database Gamma scan and profilometry needs digitization (FIPD)

Radiography unavailable - store all radiographs (rescan for higher resolution) image analysis - swelling homogeneity (radial and axial) 


\section{LDRD Concept}

Fuel Qualification - Use swelling/cladding creep data for validation of models

Allowable strain

Fuel pin bundle interactions 


\section{LDRD Concept}

How do we help to allow database to help?

\section{Example - Fuel Swelling :}

1. Modeling (axial/diametral) $\rightarrow$

2. Fuel qualification support

a. axial growth

b. stress on cladding (cladding deformation) 


\section{IMIS Data Use - example -axial growth}

Neutron Radiography- Full pin with ruler.

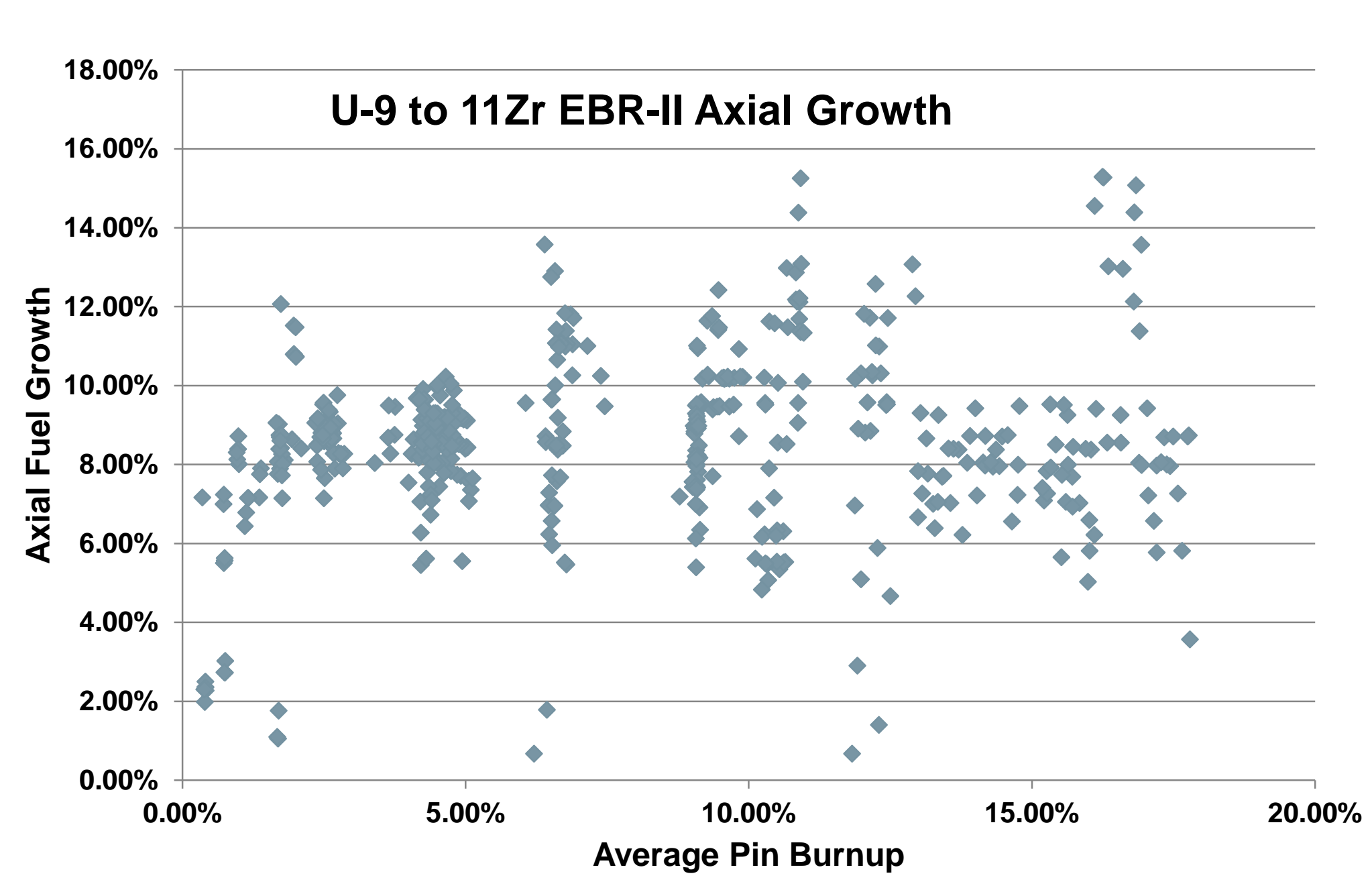




\section{IMIS Database and other Data}

\section{Start with radiograph - Mk-IV, U10Zr-HT-9:}

X448A - EBR-II Mk-IV - HT-9 clad Coldest assembly

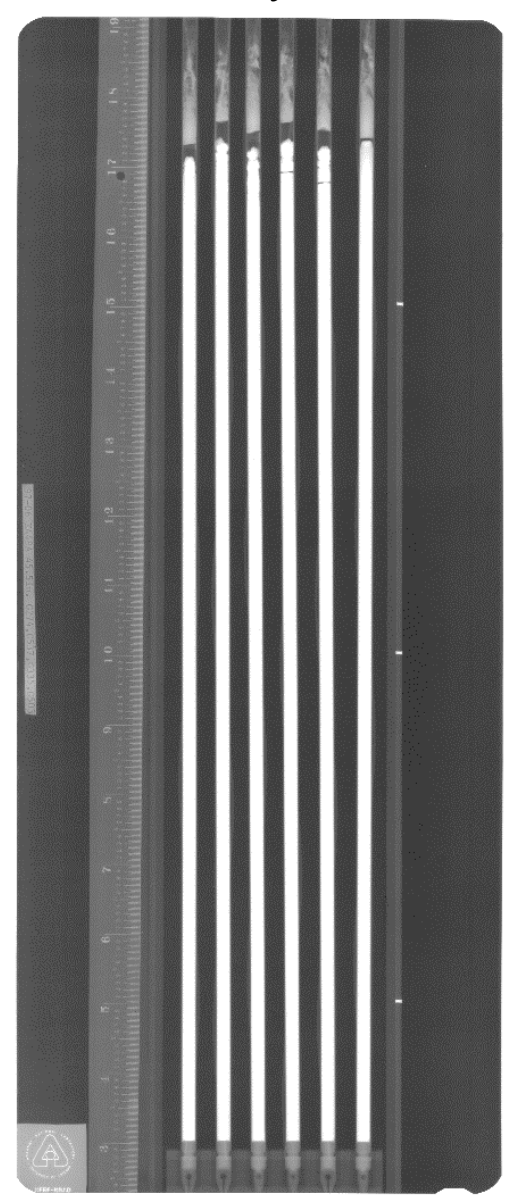

X448 - HT9 U-10Zr - MK-IV Qual

G451

G528 I G530 I G492 I G504 I G517 E

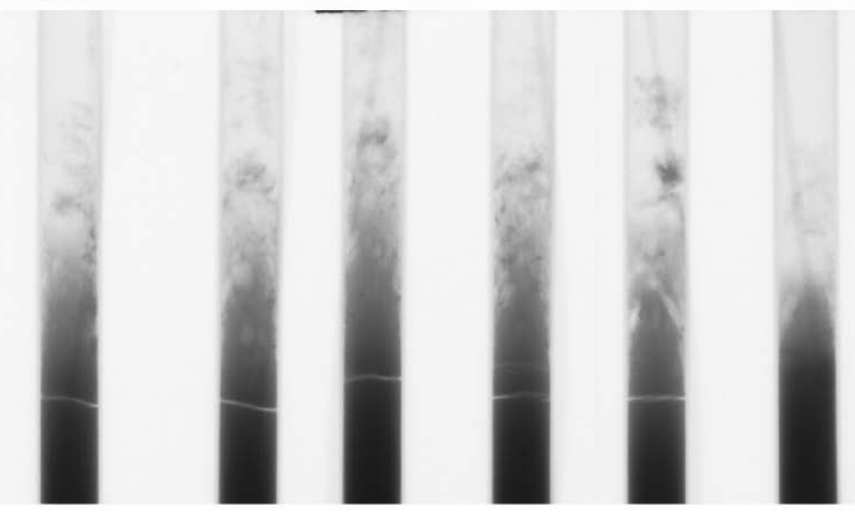

G263 E G260 I

G466 I G308 I G454 I G495

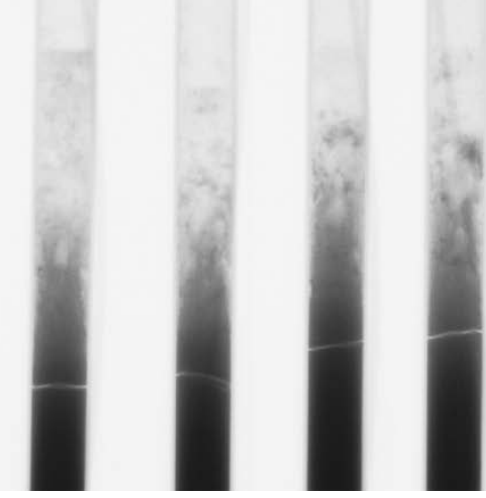

X451, X451A U-10Zr - HT-9 MK-IV Qual 2-sigma, hot assembly G418 I G391 I G364 I G356 C

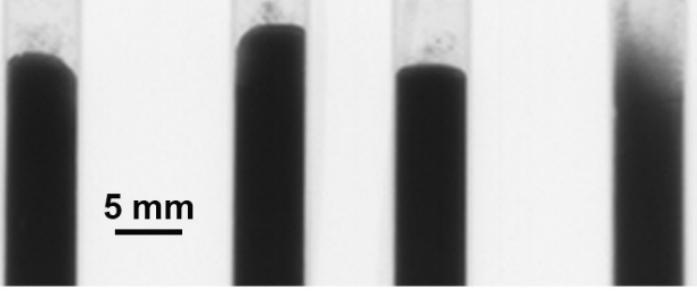

G381 | G394 | G378 | G400 | G366 | G350 | X451A

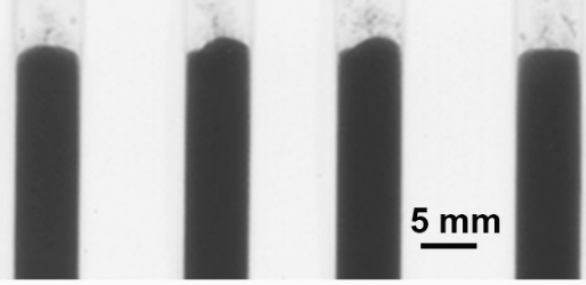




\section{IMIS Database and other Data}

\section{Start with radiograph - Mk-III:}

$$
\begin{gathered}
\text { X438 - D9 U-10Zr - MK-III Qualification -2-sigma, hot } \\
\text { assembly }
\end{gathered}
$$

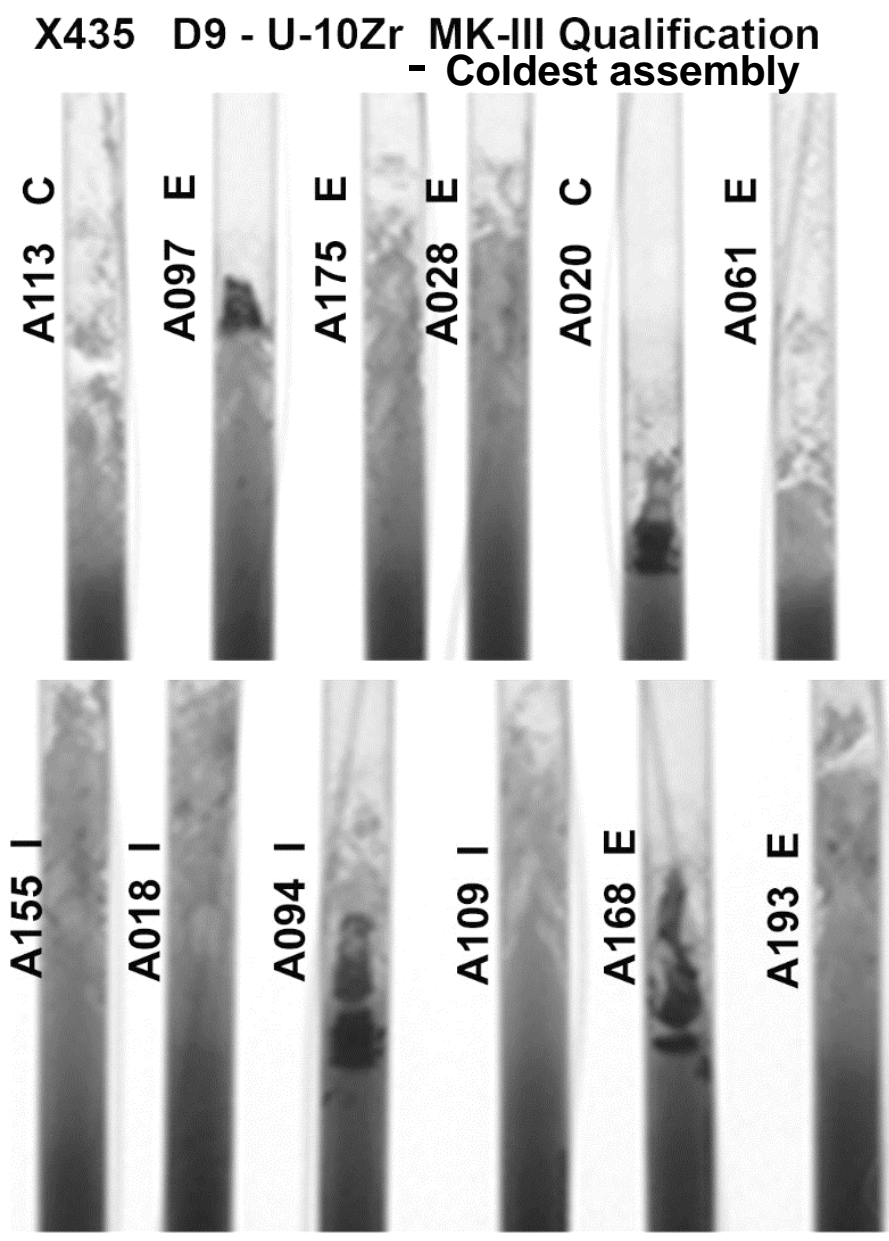

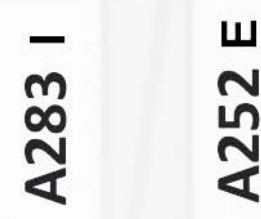

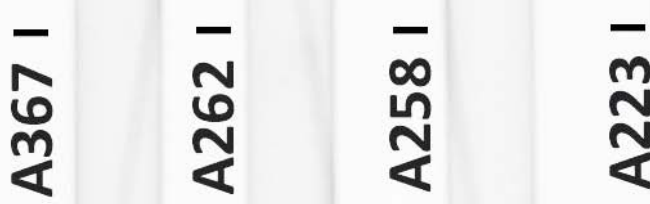

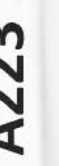


IMIS Database and other Data

Start with radiograph:
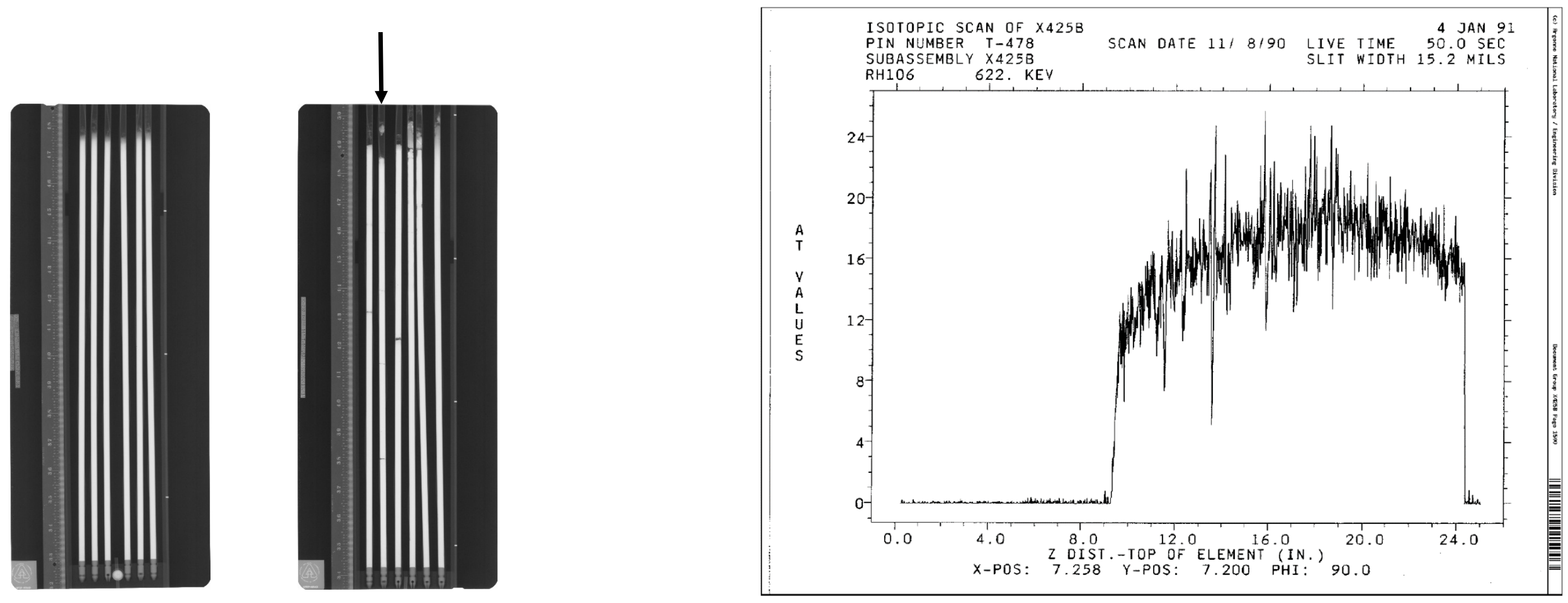

Pin T-478 from X425B - gamma scan Rh-106 
IMIS Database and other Data

Compare radiograph with $\mathrm{Rh}-106$ gamma scan:

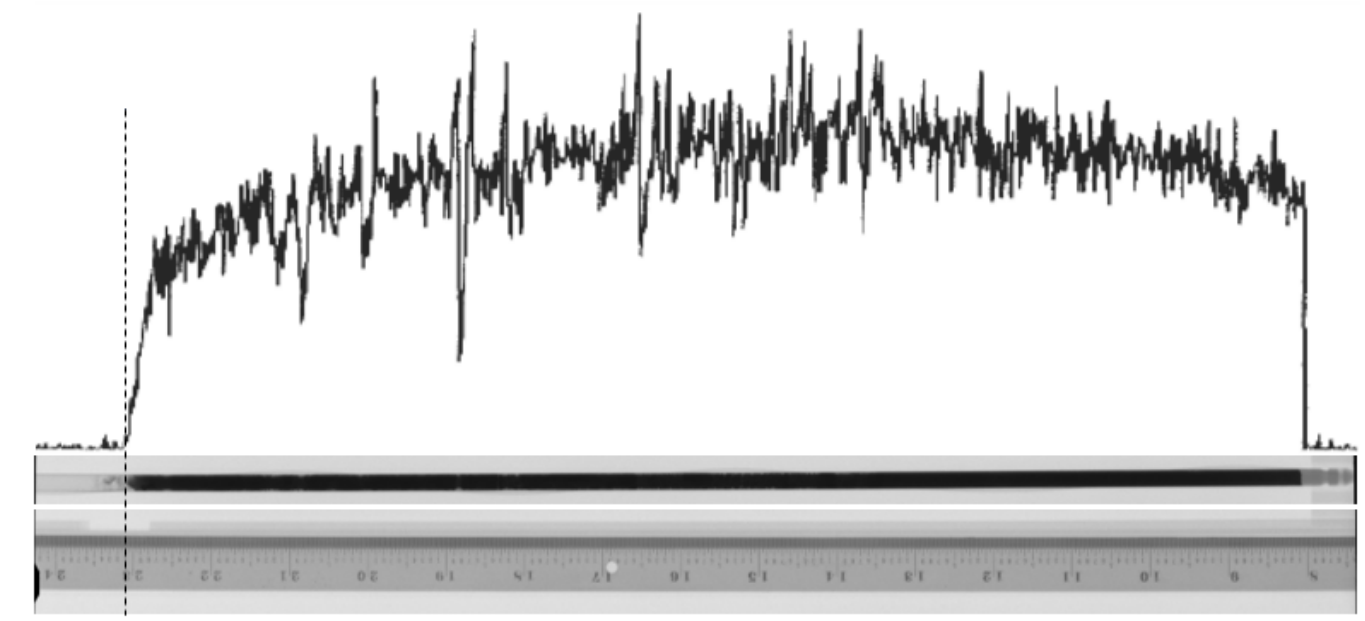

Rh-106 gamma scan superimposed on radiograph

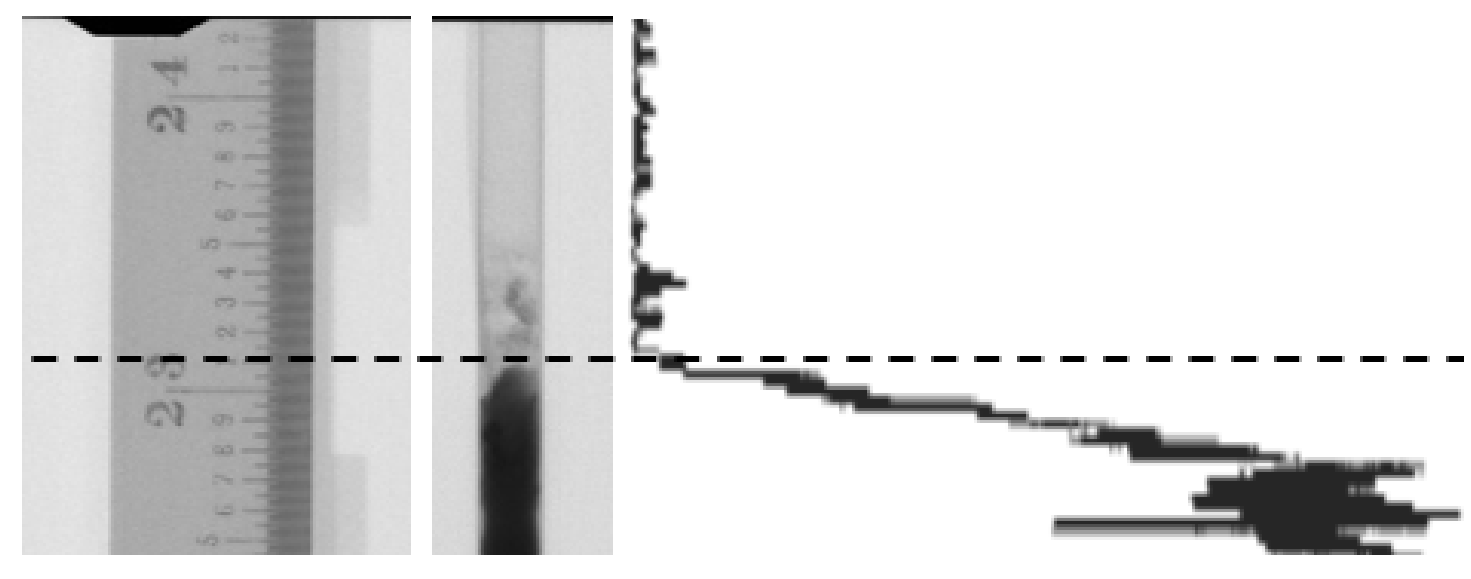

Compare end of pin with Rh-106 drop-off

Questions: Does Rh-106 in bulk follow burnup gradient? How much 'fluff' to count - (2\% swelling variability here) 
New for LDRD in FY20

This year use of 'Big Data analytics' has been added to LDRD.

Machine Language based metallographic image/radiograph feature-extraction and feature-selection tool from radiographic and microscopic images will be implemented into MOOSE so that it can be accessed by MARMOT and BISON

Example (radiography): as simple as rapid selection of axial growth data, or zone formation, radial and axial image density changes, 


\section{Where to go from here (after this workshop)}

With collaboration and sharing information we strengthen whatever the database(s) evolve into.

Seeing FIPD will change our LDRD as it may accelerate us to our goals.

FIPD could be enhanced with neutron radiograph, drawings, FFTF PIE data

Should newer AFC data be added, new PIE on old pins, ATR experiments?

Should other fuel types be included in the future?

Are there issues with collaboration: color of money (LDRD and ART Program), final goals and release of information 